\title{
NuNCA MÁS: EXPERIENCIA COLECTIVA \\ Y LEGADO ARGENTINO DE LA MEMORIA
}

Never Again: Argentine Collective Experience and Legacy of Memory

\section{Alejandro Kaufman Instituto Gino Germani (Argentina)}

RESUMEN: Se examinan las nociones de genocidio y exterminio como discontinuidades a la luz de la experiencia argentina de los desaparecidos, en el contexto contemporáneo de la globalización. Se aborda la fórmula del nunca más en relación con la noción de discontinuidad. Se analiza la singularidad argentina en relación con la postdictadura y las transformaciones que se requiere analizar en tanto acontecimientos de la memoria. El legado de la memoria no remite a un hecho concluido del pasado, sino a un proceso continuo de transformaciones en curso.

Palabras clave: nunca más, memoria, violencia social, genocidio.

RESUM: En aquest article s'examinen les nocions de genocidi i d'extermini com a discontinuïtats a la llum de l'experiència argentina dels desapareguts, en el context contemporani de la globalització. S'hi aborda la fórmula del mai més en relació amb la noció de discontinuïtat. S'hi analitza la singularitat argentina en relació amb la postdictadura i les transformacions que es requereix analitzar en tant que esdeveniments de la memòria. El llegat de la memòria no remet a un fet conclòs del passat, sinó a un procés continu de transformacions en curs.

Paraules clau: mai més, memòria, violència social, genocidi.

ABSTRACT: The article examines the notions of genocide and extermination as discontinuities in light of the Argentine experience of the desapareci- 
$d o s$, in the contemporary context of globalization. The formula never again is addressed in relation to the notion of discontinuity. The unique characteristics of the Argentine case are analysed in connection with the post-dictatorship and the changes that need to be discussed as events concerning memory. The legacy of memory does not only refer to a notable past event; it concerns a continuous process of transformations in progress.

KEYWORDS: never again, memory, social violence, genocide.

$A_{\text {argentina suele periodizarse a partir de la fecha del golpe de estado del }}^{\text {unque el ciclo contemporáneo de la experiencia colectiva anamnética }}$ 24 de marzo de 1976, y no obstante que se puede también incluir un breve lapso previo durante el cual la represión exterminadora ofreció un pródromo ( $c f r$. el Operativo Independencia, la Triple A), también podríamos indicar como momento fundacional de la experiencia colectiva contemporánea el surgimiento de las Madres de Plaza de Mayo, en abril de 1977. No parece ofrecer mayores dificultades la propuesta de señalar como hito la emergencia de las Madres por múltiples razones que, por ser muy conocidas, podrían eximirnos de revisarlas en el presente trabajo. Sin embargo, conviene destacar dos notas distintivas que, a nuestro parecer, justifican un señalamiento específico: no se trataba en su origen de un activismo ni de una militancia, política ni de derechos humanos. Sin precedentes, en general, surgió a partir del reclamo de la suerte de los desaparecidos, cuando aún no se tenía noción alguna de lo que precisamente estaba sucediendo, y quienes participaban de lo que emergía como movimiento social se definían por su vínculo filial, inicialmente sin connotaciones políticas conscientes o explícitas, por lo cual dispusieron de un relativo y reducido margen de acción en el contexto del terrorismo de Estado que asolaba la Argentina desde hacía un año. No sólo no había entre las Madres una noción de lo que estaba sucediendo con la represión, sino que además en términos generales tampoco sabían acerca de la militancia 
de sus hijos desaparecidos en cuanto dicha militancia se caracterizaba por la clandestinidad, y por la omisión en el ámbito familiar de las prácticas que pondrían en riesgo a quienes finalmente sufrieron los horrores de la represión. Ese doble desasimiento, en primer lugar respecto del sentido que tenían las ausencias y luego de las razones por las que muchos de sus hijos corrían riesgos, les otorgó a las madres, sin perjuicio del heroísmo del que tuvieron que estar munidas para siquiera asomarse al umbral del aparato del horror, de una viabilidad que asumieron del modo que conocemos y admiramos (Bonafini, 1985). Todo ello, no sin haber pagado el tributo de la represión y las desapariciones sobre sí mismas. Entre las desapariciones de que fueron víctimas se contaron Azucena Villaflor, fundadora de las Madres, y las monjas francesas Alice Domon y Léonie Duquet.

El otro rasgo significativo de la emergencia de las Madres en 1977 es el carácter precoz de su desenvolvimiento en un contexto de parálisis social y política, en una sociedad transida por el horror, sumado en su conjunto el cataclismo que para la Argentina significó la dictadura de 1976, y que no podría menoscabarse. No ha sido motivo de frecuente análisis la desproporción verificable en la dictadura entre su capacidad de someter a la sociedad argentina a condiciones extremas de sujeción y terror, a la vez que el Gobierno del «proceso» mostraba un carácter relativo de escasa consistencia y organicidad en comparación con otros sucesos homólogos, como fue el caso chileno liderado por Augusto Pinochet, liderazgo que se prolongó aún mucho más allá de la finalización institucional de la dictadura en el país transandino, por citar un contraejemplo. En el caso argentino, en cambio, durante el transcurso de siete años de dictadura se alternaron cuatro presidentes distintos, se emprendió una guerra torpe y funesta que terminó en derrota catastrófica y a los pocos meses de su inicio, ejercieron resistencia madres de desaparecidos frente a las cuales fue creciendo la erosión del régimen sin que pudieran neutralizar un movimiento que adquirió estatura mundial. Todo ello sin perjuicio de haber verificado uno de los dispositivos de terror, censura y barbarie más atroces de que se tenga registro.

Aunque la relevancia analítica de periodizar de tal manera el ciclo de la memoria, la verdad y la justicia en la Argentina del presente puede ser ampliamente discutible, dado que ningún aspecto de lo acontecido en estos 
años ha estado exento de debates (no siempre) prolíficos y muy intensos ( $c f r$. vVAA, 2008; del Barco y García, 2010), el sentido de lo que intentamos considerar adquiere forma si damos cuenta de la eventualidad de un cierre o conclusión del período, en términos de la consecución de un proceso anamnético que hemos desarrollado en otra parte y que recientemente se ha manifestado de nuevas maneras en cuanto al desenvolvimiento en el tiempo de una discontinuidad originaria (White, 2010; Kaufman, 2012; Tozzi, 2012). El acontecimiento de la desaparición de personas tenía como una de sus notas distintivas la completa omisión de toda referencia pública o institucional por parte del Estado responsable respecto del destino de los desaparecidos omisión que se mantuvo hasta el presente por parte de los perpetradores-. Sobre ese plano incidió un movimiento social emergente ejemplar como el de las Madres (como parte de un espacio social más amplio y creciente), a partir de una demanda de paradero hacia una institución estatal que se manifestaba como casualmente ajena y sin respuestas frente a los requerimientos planteados. El marco de la movilización social por el destino de los desaparecidos dio lugar al surgimiento inédito y radical de un manantial de producción de significaciones que atravesó a la sociedad argentina hasta la actualidad, y la proyectó en el escenario global en un sentido ejemplar en relación con las problemáticas de memoria y derechos humanos.

Cuando en 2006 se declaró como crimen de lesa humanidad el atentado con bomba contra la AMIA, ocurrido el 18 de julio de 1994, por primera vez se incorporó a la trama jurídico-política de la memoria y los derechos humanos un evento no relacionado con el terrorismo de Estado de 1976. Ningún régimen político totalitario impidió declarar de tal manera el atentado con anterioridad, ni tampoco lo fue el que impidió todo progreso en el esclarecimiento de la causa hasta la actualidad. Tampoco un atentado con tales características nos remite a un novum como el que estableció la figura del desaparecido. El atentado contra la AMIA tuvo un carácter inaugural a nivel global que no fue del todo registrado como tal en tanto ocurrió en un país periférico y muy distante en todos los aspectos - distancia tanto geográfica, como simbólico-política - del conflicto del Medio Oriente al que estaba siendo convocado, y de los centros del poder global que establecen las agendas dominantes (Lutzky, 2012). El estallido semiótico que produjo la muerte del fiscal del caso AMIA el 18 de enero de 2015 introdujo una nueva significación susceptible de implan- 
tar un eventual hito en el decurso argentino de la memoria al insertar un evento bélico-político anónimo como el atentado en la malla tejida alrededor de la interrupción de 1976. Políticas de estado de memoria y derechos humanos se vieron interpeladas por un suceso elevado como atinente al mismo campo discursivo que hilvanó el rumbo del nunca más entre 1977 y 2015.

\section{II}

Discontinuidad: modo de dar cuenta de una anomalía, una interrupción en el curso de los acontecimientos, una fisura que introduce una distinción radical entre formas inconmensurables de violencia. En un polo sabemos o creemos saber que se encuentra la guerra; en el opuesto, el genocidio o exterminio. Suele darse más o menos por sentado qué se entiende por guerra, como si se tratara de un intercambio reglado en el que pudiera determinarse desde afuera sobre la contención y el exceso: «[...] la brutalidad extrema y la violación de todos los derechos de combatientes y no combatientes no son un resultado normal de su desarrollo» — subrayado mío- (Burucúa, 2004, pág. 216). Sin embargo, encontramos que en la guerra «antes de la invención de los explosivos, los propios límites del poder muscular recortaban su nocividad; e incluso durante algún tiempo después, las inhibiciones morales, alimentadas por la percepción de la escasa nobleza que había en añadir elementos mecánicos y químicos al poder del hombre para lastimar a su hermano, sirvieron para restringir las barbaries deliberadas que hubiese en el diseño» (Keegan, 2013, pág. 354). Pero a pesar de la instauración de codificaciones para limitar el uso del gas venenoso o las balas explosivas, «el auge de armas "mata cosas" en oposición a las armas mata personas - la artillería pesada es un ejemplo - invalida estas limitaciones, debido a que los efectos secundarios causan grandes daños y desfiguraciones. Las limitaciones, en consecuencia, han sido abandonadas; $y$ un efecto muy perseguido ahora por las armas mata personas es causar las heridas más terribles y aterradoras que se pueda» (Keegan, 2013, pág. 354).

El término propuesto inicialmente como discontinuidad respecto de los acontecimientos de la violencia fue el acuñado por Raphael Lemkin, genocidio, para referirlo a sucesos excepcionales y distinguibles de las prácticas 
bélicas en cuanto a la distinción entre confrontaciones violentas entre colectivos armados (estatales) y aniquilación de grupos nacionales. El inmenso proceso testimonial, filosófico, político, literario y antropológico que cuenta en su repertorio a Adorno, Celan, Levi, Arendt, Agamben, entre tantos y tantos otros, y que podríamos referir a la noción del nunca más, no aplicable sin más a masacres, guerras ni atentados, no daba cuenta ni del paradigma punitivo de la memoria, ni tampoco de las prácticas de violencia propias de las confrontaciones conocidas en la historia cultural desde sus albores. Probablemente haya llegado la hora de consignar, es nuestra hipótesis sólo esbozada aquí, las continuidades entre guerra y genocidio en nuestra época, por una parte, y las discontinuidades entre dispositivos biopolíticos de gestión de la vida y la historia cultural antecedente; donde la discontinuidad no remite a una descripción factual sino a un enfoque ético-político sobre el presente, es decir a una crítica radical de la cultura contemporánea, atenta al Apocalipsis (Girard, 2010). Una cosa es segura: el ciclo que va de Videla a la AMIA nos indica que la distinción binaria entre terrorismo y guerra legítima o justa, o la que se le opone, entre el Imperio y «los pueblos» son una forma de designar la guerra civil en curso. Para una discusión sobre memoria y derechos humanos se nos impone un tercer camino, hoy no trazado aún, no obstante la esperanza que nos otorga el legado.

\section{III}

¿Cuál es la trama que se ve fracturada, y en qué consiste la interrupción que llamamos discontinuidad? Se produce una interrupción en el curso de los sucesos histórico-políticos de naturaleza discontinua respecto del estado de la conciencia colectiva que la antecede. En ello reside una diferencia con la guerra, tal como la concebimos aún en cuanto significación, la cual reconoce condiciones precedentes identificables sin las cuales el evento bélico no podría tener lugar, dado que requiere contendientes deliberados que constituyan la confrontación. Un colectivo víctima de aniquilación no es contendiente porque es privado de las condiciones o los medios que darían lugar a una confrontación. Esta privación es sólo resultado de la deliberación del perpetrador, que coloca a las víctimas ante un escenario sin alternativas, una trampa letal. 
A diferencia de los crímenes de guerra, que tienen lugar — como premisaen un escenario bélico reconocible por los contendientes, la aniquilación, tal como sucedió en los sucesos paradigmáticos (cfr. Agamben, 2009, en particular: «¿Qué es un paradigma?», págs. 13-44) no fue anunciada como tal, y las víctimas fueron conducidas a situaciones acerca de las cuales no se pudieron prevenir, porque les fueron sustraídos los recursos que habrían posibilitado evitar tales consecuencias.

Abordamos categorías emergentes y cambiantes en escenarios a su vez en transformación, con incertidumbres de diverso grado acerca, ya no sólo del futuro, sino incluso de cuán cognoscible es el presente, en tanto el objeto en discusión fue clandestino, sustraído al conocimiento público en el pasado reciente, y descubierto en una fecha determinada. Múltiples problemas plantea discutir qué se sabía mientras acontecía el exterminio, y qué y cómo se supo cuando se supo, y qué sucede con el conocimiento en el contexto de la memoria y el olvido. No disponemos para el tema de categorías susceptibles de otorgarnos puntos de reparo, puertos donde descansar antes de seguir viaje. Si Lemkin instituyó la definición de genocidio en 1944, un año después estallaron las bombas de Hiroshima y Nagasaki. Si desde entonces no ha vuelto a emplearse el armamento nuclear, el que está disponible en los arsenales es suficiente para destruir la civilización tal como la conocemos varias veces, y no sabemos tampoco si en el minuto siguiente a la redacción de las presentes líneas no habrá una conflagración nuclear, ya sea por accidente o por acciones terroristas. Al menos podemos confiar hasta cierto punto en que los estados que cuentan con arsenales nucleares no se han apartado hasta ahora de doctrinas disuasivas, conscientes de la inviabilidad - civilizatoria, ya que no técnica - del uso del armamento nuclear. No obstante, las incertidumbres tienen entidad catastrófica, sin contar con que otros actores políticos y estatales aspiran a armarse con este tipo de artefactos de destrucción masiva (lo cual no suma ni resta nada en el plano moral, solo aproxima el peligro). De ahí que necesitamos establecer analíticamente reparos, puntos de anclaje que aporten certidumbre frente a un escenario desolador, aun cuando sólo sean recursos de emergencia, tablas de salvación. Es una necesidad que nos concierne, no ya como analistas, sino como ciudadanos, como agentes sociales y como sujetos de la memoria. 
En ese sentido, el enunciado del nunca más opera como un articulador de interrogantes y descripciones que hallamos apropiados para transcurrir en la dirección indicada. Sin perjuicio de que para discutir esta cuasi categoría es necesario despejar antes dos aspectos. En primer lugar, el uso banal, muy extendido, por el que se lo aplica a eventos que han tenido lugar desde siempre y seguirán ocurriendo mientras el mundo conocido no cambie en forma correlativa. La institución de la fórmula nunca más vino a declarar la determinación de que los acontecimientos del horror no se repitan. No lo hizo como mera declaración de propósitos sino como compromiso con la verdad y la justicia en tanto necesidad socio-política y cultural contra la barbarie y por la convivencia. Desde su instauración la fórmula vino a invocar las acciones y los debates requeridos para que acciones eficaces, contextos culturales, intelecciones estéticas y políticas construyeran las condiciones apropiadas para prevenirnos de la repetición. Múltiples catástrofes éticas acontecidas desde 1945 parecen denegar toda verosimilitud a este pronunciamiento, hasta para ponerlo en tela de juicio para las fechas, hace ya varias décadas, en que fue adoptado en la Argentina por el movimiento de derechos humanos y por extensión el conjunto de la sociedad. Se necesita entonces definir cuáles son las condiciones para dar sustento al enunciado, conferirle credibilidad. En el caso argentino se abrieron dos líneas de interpretaciones y acciones. La jurídica, orientada al castigo de los culpables de los crímenes, y la político-institucional-educativa. Ambas han dado frutos, así como plantean diversos problemas, contradicciones y paradojas. No obstante, se articularon de modo en general coherente con la configuración de la discontinuidad, con el propósito de que no se repitan los acontecimientos que fueron inéditos, que no forman parte de las condiciones antropológicas constitutivas, como es el caso de la guerra, el delito «común» o los accidentes. Por poco deseables que los consideremos, no los incluimos en términos del propósito de que no tengan lugar una y otra vez en el mismo orden que los acontecimientos del horror. Pero aquí es donde hay que decir que las condiciones según las cuales podemos esperar que algo no suceda demandan distinciones explícitas. Por ejemplo, una condición para suprimir las guerras es eliminar los armamentos. Una destrucción y prohibición absolutas y eficaces de todos los armamentos (sueño de la humanidad desde hace milenios, aunque pocas veces se haya puesto en práctica) no garantizaría la supresión de la guerra, pero manifes- 
taría sin duda una disposición sustentable para que no suceda. No podemos decir de manera seria y sustentable «nunca más» en relación con la guerra si a la vez fabricamos armas y administramos arsenales y ejércitos. Se trata en este punto de determinar cuáles de las condiciones que han hecho posibles los acontecimientos del horror se deben y se pueden suprimir, y efectivamente se han suprimido.

En segundo lugar cabe analizar el carácter ambivalente de la fórmula, ya implícito en la persecución penal de los perpetradores, frente a los cuales los testigos y sobrevivientes, apoyados en la institución estatal posterior a los acontecimientos del horror, y determinada a sustentar en forma eficaz la fórmula ( $\sin$ lo cual no habría posterioridad genuina respecto de los acontecimientos del horror, sino continuidad) son actores necesarios para el juicio y castigo de los culpables, en procura de prevenir la impunidad de los crímenes. Vemos en este punto que a la discontinuidad definida por los acontecimientos del horror en cuanto a su carácter inédito respecto del pasado reciente y remoto, le debe suceder un acto a su vez discontinuo con el orden del horror, consistente en lo que se establezca como reparación. Sin una delimitación eficaz, que puede variar según los casos y las circunstancias históricas, no tendría sustentación la fórmula de la no repetición. Pero a la vez la reparación no borra el trauma ni la memoria. Lo sucedido tuvo lugar, aconteció, y no se puede volver atrás. La ambivalencia procede de que quienes atravesaron una experiencia de inermidad, abandono, inclemencia, desamparo se alzan ante sus verdugos, ahora en el banquillo de los acusados, con la fuerza de la ley. Tal ambivalencia no se registra, como es obvio, desde el punto de vista jurídico e institucional, sino existencial, plano en el que se presentan contingencias de naturaleza bien diferente, no exentas de sus respectivas incertidumbres.

El interrogante sobre el nunca más, entonces, refiere a aquellas condiciones materiales que formaron parte del dispositivo exterminador y que en lo sucesivo no habrán de repetirse. El espectro de estas condiciones es muy amplio y complejo, y su tratamiento supone prácticamente un análisis cultural radical del presente. Al menos es más viable determinar ciertas condiciones mínimas, que sin duda no habrán de ser satisfactorias: las cámaras de gas, o sus huellas, forman parte solamente de los museos y de los libros de historia, y creemos que nada similar forma parte de nuestro mundo contemporáneo. 
Basta enunciar esto para verificar la ausencia de certidumbres, así como la inconveniencia de alentar cualquier optimismo ingenuo, sobre todo porque aquello que se repita lo hará bajo otras formas, inesperadas para nuestra deliberación consciente. Por lo tanto, la fórmula no conduce a un repertorio explícito e inequívoco, sino a debates sobre las condiciones cambiantes de la cultura y la tecnociencia, respecto de procesos y dispositivos emergentes, acerca de los cuales sabemos cuánto alientan los peores temores, antes que una ingenuidad optimista: «no existe nada en la historia que se parezca a una apropiación o a una instalación en el "reino" de lo universal, del modo en que los filósofos clásicos pensaban que el advenimiento de los Derechos del Hombre y del Ciudadano podía representar un punto de no retorno, el momento cuando el hombre se convertía en los hechos en portador de lo universal que ya él mismo era por destino» (Balibar, 2013, págs. 64,65). Dispondríamos entonces, en el peor de los casos, de una categoría analítica y, en el mejor, de un discurso competente al menos para reducir el daño. Dicho esto, entonces, nos vemos reducidos a declararnos en estado de relativa continuidad con los acontecimientos del horror, en el ejercicio de un criticismo que exige una señalada perseverancia.

\section{IV}

Por fin, la fórmula es consecuencia primera de un acaecimiento inesperado, por no esperable, por no componible con lo concebible, lo imaginable, pero además sustraído al conocimiento público, es decir, secreto, clandestino (Lyotard, 1988). La fórmula se pronuncia a partir de un punto en el que se vuelve evidente algo que, o estaba oculto en su concreción, o no se le atribuía todavía o del todo el sentido que más tarde se tornó indudable. Los acontecimientos del horror, paradigmáticos del origen de la formulación del nunca más no fueron objeto del conocimiento público en el momento en que tuvieron lugar. Ésta es una afirmación que no puede sino estar atravesada por nuestra pertenencia a una actualidad espectacular hasta la saturación. También esta caracterización es problemática. Sin embargo, su materialidad se verifica en que hay un intervalo temporal en el que se produce una revelación sobre lo acontecido y acerca de lo cual se considera hasta cierto punto verosímil que 
antes (es decir, durante) no se supiera, y en un momento dado se descubre lo que había ocurrido y se mantenía fuera de la visibilidad pública. No obstante todo lo discutible que puedan ser estas descripciones, hay una escena de revelación, como la que tuvo lugar paradigmáticamente, y se conmemora, en la liberación de los campos de exterminio nazis. Hay una significación, representaciones e iconicidad en el horror puesto a la luz del día, y frente al cual se pone en evidencia algo que no se sabía de antemano. Esta figuración es una de nuestras pathosformeln, identificable en nuestras ficciones contemporáneas. El horror mantenido en secreto que se descubre súbitamente, que había estado hasta ese momento a salvo de la visibilidad pública, y que revela en ese instante lo insoportable, lo inaceptable de la presencia del mal.

Sabemos cuán relativo es este desconocimiento, cuánto tuvo en su momento de complicidad, negligencia, culpabilidad. A ello se añade que los acontecimientos del horror no bajaron del cielo, no surgieron por generación espontánea, que la serpiente primero tuvo la forma del huevo, o dicho en forma más apropiada: existieron precondiciones dóxicas (Angenot, 2010). Categoría que se suma a la agenda del nunca más para prevenir que se repita, al adoptar frente a los discursos circulantes una actitud crítica, preventiva. Desde luego, tampoco estamos en este punto en el mejor de los mundos, sino todo lo contrario, dado que en la actualidad vemos aflorar discursos de incitación al odio por doquier, sin que las fuerzas democráticas o de prevención de nuevos horrores consigan la eficacia que se requeriría para neutralizar o atenuar de mejor manera tantas manifestaciones preocupantes de violencia simbólica que circulan al abrigo de las nuevas tecnologías de la viralización.

Los últimos años han dado cuenta sin embargo de que la repetición de acontecimientos del horror encuentra una variación homóloga a las del pasado en el orden de la tecnociencia, vinculada, como se sabe, y se ignora y olvida tanto, con las industrias de la guerra, acogido todo ello bajo el velo del secreto, o del semisecreto, y por lo tanto susceptible de revelaciones atroces, o del uso de tales gramáticas plausibles para justificar de modo falaz y deslegitimador de cualquier discurso institucional la pasada invasión a Irak o un futuro ataque contra Irán, por ejemplo. Subsiste entonces un régimen discursivo que guarda continuidad con el pasado reciente y respecto del cual estamos prevenidos, al menos en términos conceptuales y perceptivos. Nos 
resulta inteligible que cualquier poder estatal guarde secretos atroces, ya sea en los resguardos concentracionarios que atrapan inmigrantes ilegales en Europa, entre los secuestrados en Guantánamo o en los túneles excavados en montañas persas.

Al contrario, mientras en la segunda mitad del siglo xx imperaba la fórmula del nunca más, con su reactividad frente al secreto y su lógica de la discontinuidad, a la vez emergía como una nueva modalidad de estructuración del poder, la llamada sociedad del espectáculo. Basta de secretos entonces, ahora el pasaje a la hipervisibilización. Desde luego, transformaciones de esta naturaleza no se producen de un día para el otro, ni se aprecian ni advierten en toda su magnitud al mismo tiempo que se desenvuelven. La crítica no se equivocó cuando dictaminó la condición sociocultural del último tercio del siglo xx en términos de transparencia y visibilidad industrialmente generalizadas. Sólo que tuvieron que suceder varias cosas para configurar el paisaje de la actualidad. Tuvieron que caer un muro y una cortina de hierro, caídas alentadas por el régimen de visibilidad y transparencia frente al cual el ocultamiento adquirió sucesivamente mayores grados de inadecuación y rechazo, y luego tuvieron que ser demolidas las torres de Nueva York, terror acontecido ahora en la televisión y en vivo, en tiempo real, visible y transparente.

Nuevos perpetradores de horrores, entonces, no recurren al secreto, sino a la visibilidad. No recurren — al menos del modo usual — a las tecnociencias, ni a la industria de la muerte biopolítica, sino a la industria del espectáculo, hipermoderna, para exhibir prácticas de violencia pre y antimodernas. Las formas modernas de la violencia, a partir del terror suscitado por la revolución, imponían la supresión del dolor: la guillotina, instantánea decapitación anestésica, humanitaria forma de dar la muerte indolora deja su lugar ahora a la decapitación practicada como suplicio, pero no en secreto sino filmada con técnicas de montaje espectacular y viralizadas por las redes sociales de las vanguardias tecnológicas. Quienes perpetran estos nuevos crímenes han leído atentamente la formulación del nunca más. Se adelantan a otros que se esmeran en proponer políticas de estado de negacionismo del holocausto mientras negocian el secretismo tecnocientífico bélico: permanecen en el siglo xx, todavía. Las nuevas formas del horror, ya inspiradas en las guerras postcoloniales televisadas de las grandes potencias, incorporan una apela- 
ción a la inimputabilidad en cuanto al ambicioso y complejo aparato jurídico de los derechos humanos. Recurren a las prácticas de violencia criminal de remota antigüedad y refuerzan el horror ante lo inesperable. Esto es inédito, no expectable y por lo tanto horroroso, no porque no fuera representable o inédito o imaginable, sino porque esas prácticas de violencia habían quedado atrás, en el pasado remoto, y ya no volverían a suceder. Formaban parte del nunca más del progreso y la modernidad. Afrontamos una creativa respuesta al nunca más, porque sucede lo que se daba por sentado que no iba a suceder, y era concebible porque formaba parte de remotas memorias históricas, museos y ficciones. Pues todo eso sucede ahora, ante nuestros ojos, y aterroriza porque contiene como amenaza la restauración de aquellos horrores del pasado de los cuales nuestros tiempos modernos nos habían preservado. Mientras estábamos ocupados previniéndonos de los horrores de los acontecimientos modernistas (White, 2010), se nos combate con los horrores superados del pasado remoto, de los que sólo teníamos una memoria ficcional e histórica. Al exponernos a las imágenes de esa brutalidad recuperada del pasado, restaurada como un fantasma, se nos enfrenta con lo inesperable, del modo en que lo inesperable acontece, no como repetición de lo mismo sino bajo forma incomponible. Si discutíamos sobre lo real y lo ficcional, en particular acerca de la memoria atinente a los acontecimientos del horror del pasado reciente, también ese debate es contestado por estas nuevas imágenes: recurren a los dispositivos ficcionales de la industria del espectáculo, los mismos que la crítica cultural denostó hasta el cansancio moral y sin mucho éxito político, para violentarnos en estos nuevos campos de batallas semióticas, en las cuales el poder se ve impelido como primera medida de respuesta a establecer ¡la autenticidad de las imágenes! Mientras se nos viralizan decapitaciones brutales, el ejercicio del poder consiste como primera respuesta en validar esas imágenes.

Nos encontramos entonces frente a un corolario provisional: la fórmula del nunca más no da cuenta empíricamente de la totalidad - aunque sería desaconsejable descuidarse: la historia social no es unívoca; como el agua, transita por donde mejor gravite, por donde menor resistencia encuentresino que los nuevos acontecimientos organizan un escenario ante el cual las defensas existentes y las herramientas conceptuales no resultan apropiadas porque estaban destinadas a otras tácticas y estrategias de confrontación. 


\section{Referencias}

Agamben, G. (2009): Signatura rerum. Sobre el método, Adriana Hidalgo, Buenos Aires.

Angenot, M. (2010): Interdiscursividades. De hegemonías y disidencias, Universidad Nacional de Córdoba, Córdoba.

Balibar, É. (2013): Ciudadanía, Adriana Hidalgo, Buenos Aires.

Bonafini, H. D. (1985): Historias de vida. Hebe de Bonafini, Fraterna/del Nuevo Extremo, Buenos Aires.

BurucúA, J. E. (2004): «Cómo sucedieron estas cosas», Representar masacres y genocidios, Katz, Buenos Aires.

del Barco, O. Y. y C. P. García (2010): No matar: sobre la responsabilidad, Universidad Nacional de Córdoba, Córdoba.

Girard, R. (2010): Clausewitz en los extremos. Política, guerra y apocalipsis, Katz, Buenos Aires.

KAUFMan, A. (2012): La pregunta por lo acontecido. Ensayos de anamnesis en el presente argentino, La Cebra, Buenos Aires.

Keegan, J. (2013): El rostro de la batalla, Turner, Madrid.

LuTzKy, H. (2012): Brindando sobre los escombros. La dirigencia judía y los atentados: entre la denuncia y el encubrimiento, Sudamericana, Buenos Aires.

LyotaRd, J.-F. (1988): La diferencia, Gedisa, Barcelona.

Tozzi, V. y. (2012): Hayden White, la escritura del pasado y el futuro de la historiografia, EDUNTREF, Buenos Aires.

VvaA(2008): Sobre la responsabilidad: no matar, Del Cíclope/Universidad Nacional de Córdoba, Córdoba.

White, H. (2010): Ficción histórica, historia ficcional y realidad histórica, Prometeo, Buenos aires. 